\title{
Postoperative Atrial Fibrillation Decreased Long-term Survival Rate in Isolated Valve Surgery
}

\author{
Suwei Wang, Yutao Xi and MacArthur Elayda* \\ Department of Biostatistics/Epidemiology and Information \\ Technology/Medical Informatics, Texas Heart Institute, USA \\ *Address for Correspondence \\ MacArthur Elayda, MD, PhD, Department of Biostatistics/Epidemiology \\ and Information Technology/Medical Informatics, Texas Heart Institute, \\ Houston, TX, USA, Tel: 832-355-3730; Email: MElayda@texasheart.org \\ Submission: 04 November, 2016 \\ Accepted: 06 December, 2016 \\ Published: 12 December, 2016 \\ Copyright: (๑) 2016 Wang S et al. This is an open access article \\ distributed under the Creative Commons Attribution License, which \\ permits unrestricted use, distribution, and reproduction in any medium, \\ provided the original work is properly cited.
}

Methods and results: POAF was identified in 425 patients (34.5\%) of 1229 patients underwent isolated valve repair and/or replacement operation. Patients have more chances to experience POAF if they were older than 65 years old $(p<0.0001)$, Caucasian $(p=0.0017)$, with heart failure (NYHA Class $>=$ III) $(p<0.001)$, with hypertension $(p<0.001)$ or with peripheral vascular diseases $(p<0.001)$. The unadjusted fiveyear survival rate was $82.8 \%$ for patients without POAF and $71.3 \%$ for with POAF $(p<0.0001)$. An unadjusted hazard ratio for POAF was 1.85 ( $95 \% \mathrm{Cl}: 1.40$ to 2.43 ). With a propensity score-matching model, in the 406 pairs of patients under adjusted survival analysis showed significant lower survival rate in POAF ( $p=0.001)$ with the adjusted hazard ratio of 1.40 (95\% Cl: 1.01 to 1.92), compared to without POAF.

Conclusion: Our present study supported that POAF is independently associated with an increased long-term mortality in patients who had isolated valve surgery.

\section{Introduction}

Postoperative Atrial Fibrillation (POAF), the most common complications of open cardiac surgery, can be a cause of adverse effect on prognosis, including increased incidence of stroke, increased thrombosis related diseases, prolonged length of intensive care unit and hospital stay [1-4]. Although atrial fibrillation causes substantial morbidity, it is controversial whether POAF is associated with excess mortality independent of associated risk factors after cardiac surgery, especially after isolated valve surgery [5].

Most often, POAF occurs 1 to 5 days after surgery and usually has a self-limited course. Therefore, Postoperative atrial fibrillation has been defined as benign, transient, and no consequence complication. Several studies have shown that POAF was associated with short- and long-term mortality after Coronary Artery Bypass Grafting (CABG) with and without valve replacement [6-9]. However, several factors related to postoperative atrial fibrillation also predict early and late mortality, such as advanced age, severe heart failure, etc., which could be confounding variables in establishing whether POAF results in excess mortality [7].

The objective of present study is to examine the impact of POAF on long-term survival of patients who underwent isolated valve surgery with a case-matched cohort study.

\section{Methods}

Study population collection
All isolated valve surgery patients without history of atrial fibrillation between January 1997 and December 2007 in Texas Heart Institute Research Database (THIRD) were included for this study. This study was approved by the hospital Institutional Review Board. Data was abstracted with the key words of "valve repair", "valve replacement", and "atrial fibrillation". Postoperative atrial fibrillation was defined as patient who has a new onset of atrial fibrillation/flutter of any duration between operation and discharge with a diagnosis documented by physician. All cause of death was collected and followed for up to 5 years. Patients without feedback were excluded. All of variables were identified from database.

The risk factors that are associated with POAF included: Age, Gender, Race, Hypertension, Congestive Heart Failure, Diseases of the heart valves, Acute or prior Myocardial Infarction (MI), Diabetes Mellitus, Peripheral Vascular Disease, Renal Failure; Pulmonary Disease, Cerebrovascular Disease, Endocarditis, Overweight, Smoking.

Survival was measured as time (in years) to either death or last follow-up from date of surgery. All patients without follow-up data were excluded.

\section{Statistics analysis}

Baseline characteristics were reported as mean with standard deviation or as percentage of total patients in each group. Normally distributed continuous variables were compared using student t-test and Kruskal-Wallis test were utilized for continuous variables that were not normally distributed. Chi-square tests were performed for variables presented as percentages. Fitting a logistics regression model with POAF as the outcome variable and all the baseline variables in Table 1 as predictors, a propensity score matching model was developed to adjust the baseline characteristic differences between postoperative atrial fibrillation and non-postoperative atrial fibrillation groups. Logistic regression and Cox proportional hazards methods were employed to assess the unadjusted and adjusted hazard ratio of association between occurrences of postoperative AF and long-term survival rate. Survival was analyzed by constructing Kaplan-Meier curves. All statistical analyses were performed using 
Citation: Wang S, Xi Y, Elayda MA. Postoperative Atrial Fibrillation Decreased Long-term Survival Rate in Isolated Valve Surgery. J Cardiobiol. 2016;4(1): 3

ISSN: 2332-3671

Table 1: Unadjusted characteristics for patients with post AFb and non-post AFb.

\begin{tabular}{|c|c|c|c|}
\hline \multirow{2}{*}{ Characteristics } & No PostAFb & Post AFb & Unadjusted P \\
\cline { 2 - 3 } & $\mathbf{( n = 8 1 2 )}$ & $\mathbf{( n = 4 3 4 )}$ & $<0.0001$ \\
\hline Age (>=65) & $39.93 \%$ & $64.24 \%$ & 0.54 \\
\hline Gender (Man) & $59.45 \%$ & $57.65 \%$ & 0.0017 \\
\hline Race (Caucasian) & $70.52 \%$ & $78.82 \%$ & 0.81 \\
\hline Renal Failure & $16.42 \%$ & $16.94 \%$ & 0.09 \\
\hline Pulmonary Disease & $33.71 \%$ & $38.59 \%$ & 0.0014 \\
\hline Hypertension & $63.18 \%$ & $72.24 \%$ & 0.56 \\
\hline Cerebrovascular Disease & $5.10 \%$ & $5.80 \%$ & 0.31 \\
\hline Endocarditis & $8.46 \%$ & $6.82 \%$ & 0.13 \\
\hline Previous valve diseases & $87.44 \%$ & $90.35 \%$ & 0.19 \\
\hline Previous MI & $7.84 \%$ & $10.12 \%$ & 0.39 \\
\hline overweight & $54.85 \%$ & $57.54 \%$ & 0.66 \\
\hline Smoking & $66.29 \%$ & $67.53 \%$ & 0.14 \\
\hline Diabetes Mellitus & $19.28 \%$ & $22.82 \%$ & 0.0024 \\
\hline Congestive Heart Failure & $36.07 \%$ & $44.94 \%$ & 0.0079 \\
\hline Peripheral Vascular Disease & $8.58 \%$ & $13.41 \%$ & 0.0005 \\
\hline NYHA Class >= III & $72.76 \%$ & $81.65 \%$ & \\
\hline
\end{tabular}

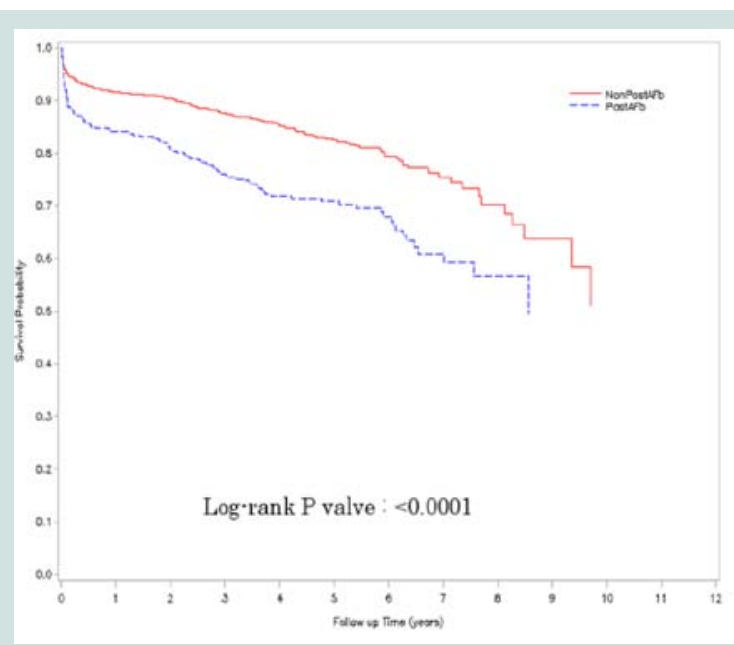

Figure 1: Unadjusted (Kaplan-Meier) curves for Post AFb and non-post AFb groups of patients.

SAS (version 9.3, SAS Inc., Cary, NC). A p value less than or equal to 0.05 was considered as statistically significant.

\section{Results}

POAF was identified in 425 patients (34.5\%) of 1229 patients underwent isolated valve repair and/or replacement operation. Patients experiencing POAF were general older $(\mathrm{p}<0.0001)$ and more likely to be Caucasian $(\mathrm{p}=0.0017)$ compared to patients without POAF. Furthermore, patients have more chances to experience POAF, if they have more severity of heart failure (NYHA Class $>=$ III) $(\mathrm{p}<0.001)$, and/or companying with hypertension $(\mathrm{p}<0.001)$ or peripheral vascular diseases $(\mathrm{p}<0.001)$ (Table 1$)$.

\section{Unadjusted survival rate}

The mean follow-up for this study was 47 months. The unadjusted survival analysis showed that the five-year survival rate was $82.8 \%$ for patients without POAF and $71.3 \%$ for those with POAF. Kaplan-
Meier survival analysis showed that there was significant difference in survival rates between patients with and without POAF $(\mathrm{p}<0.0001)$ (Figure 1). Logistics analysis revealed that POAF was a significant predictor for long-term mortality (the unadjusted hazard ratio was $1.85,95 \%$ CI: 1.40 to 2.43 ).

\section{Adjusted survival rate in propensity-matched patients}

A propensity score matching model (adjustment) was performed by adjusting for the variables listed in Table 1. Overall, 406 pairs of patients (94.6\% matching rate) was matched with all variables which has no significant differences (Table 2). The difference in the survival analysis between patients with and without POAF remained highly significant $(\mathrm{p}=0.0418)$ (Figure 2). Logistics analysis showed the adjusted hazard ratio was 1.40 (95\% CI: 1.01 to 1.92), suggesting that patients with POAF has an about $40 \%$ higher risk of death than those patients without POAF.

\section{Discussion}

The present study confirmed that POAF had a long-term impact (up to 10 years) on the survivals of patients who underwent isolated valve surgery with a case-matched cohort study, and suggested that POAF might be an independent predictor for mortality in this population.

It is well defined that the prevalence and incidence of atrial fibrillation have been associated with an increased risk of allcause mortality in population-based studies [10,11]. However, the conclusions for the effects of POAF on long-term survival still remain controversial $[4,5,9,12]$. Although most of studies showed definite association of POAF and mortality after CABG surgery few data were available on the patients who underwent isolated valve surgery $[3,4,9,13]$. Mariscalco et al. reported that POAF was not a significant predictor for late mortality after isolated valve surgery without adjusting for the risk factors [6]. However, Filardo et al. reported that POAF was associated with the long-term survival rate after surgery of aortic valve replacement either with or without CABG by using propensity score to control the risk factors [4]. However, the patients who have concomitant CABG were included in later studies, which

Table 2: Adjusted characteristics for patients with post AFb and non-post AFb.

\begin{tabular}{|c|c|c|c|}
\hline \multirow{2}{*}{ Characteristics } & No Post AFb & Post AFb & \multirow{2}{*}{ Adjusted P value } \\
\hline Age (>=65) & $55.91 \%$ & $62.06 \%$ & 0.06 \\
\hline Gender (Man) & $57.14 \%$ & $59.11 \%$ & 0.57 \\
\hline Race (Caucasian) & $77.09 \%$ & $78.08 \%$ & 0.74 \\
\hline Renal Failure & $16.26 \%$ & $17.49 \%$ & 0.64 \\
\hline Pulmonary Disease & $38.18 \%$ & $37.74 \%$ & 0.83 \\
\hline Hypertension & $67.98 \%$ & $71.18 \%$ & 0.32 \\
\hline Cerebrovascular Disease & $5.42 \%$ & $5.91 \%$ & 0.76 \\
\hline Endocarditis & $7.99 \%$ & $6.90 \%$ & 0.59 \\
\hline Previous Valve Diseases & $90.64 \%$ & $90.15 \%$ & 0.81 \\
\hline Previous MI & $8.87 \%$ & $10.10 \%$ & 0.55 \\
\hline Overweight & $57.39 \%$ & $56.90 \%$ & 0.89 \\
\hline Smoking & $67.49 \%$ & $66.50 \%$ & 0.77 \\
\hline Diabetes Mellitus & $20.69 \%$ & $22.66 \%$ & 0.5 \\
\hline Congestive Heart Failure & $41.69 \%$ & $42.86 \%$ & 0.72 \\
\hline Peripheral Vascular Disease & $11.58 \%$ & $13.05 \%$ & 0.52 \\
\hline NYHA Class >= III & $77.34 \%$ & $80.79 \%$ & 0.23 \\
\hline
\end{tabular}


Citation: Wang S, Xi Y, Elayda MA. Postoperative Atrial Fibrillation Decreased Long-term Survival Rate in Isolated Valve Surgery. J Cardiobiol. 2016;4(1): 3 .

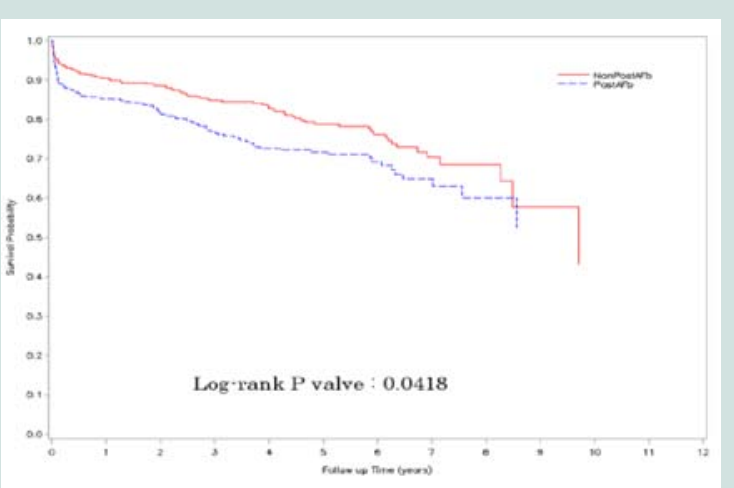

Figure 2: Adjusted (Kaplan-Meier) curves for Post AFb and non-post AFb groups of patients.

might limit the independent contribution of POAF.

In the present study, age ( $>65 \mathrm{yrs})$, ventricular dysfunction and overload, and peripheral vascular diseases showed more risk of POAF after valve surgery. Multiple underlying mechanisms in POAF related increased mortality had been proposed. POAF related dysfunction of left ventricle, and/or embolus formation and consequence of stroke might contribute to increased mortality after POAF [11,14]. Furthermore, the atrial refractoriness and subsequent generation of re-entry wavelets, which might be due to direct atrial injury from manipulation of surgery [2]. Therefore, multiple factors might be the underlying mechanism for POAF after isolated valve surgery.

Our study provides evidence that POAF was associated with long-term mortality after isolated valve surgery independently and by matching the variables between groups. In our present study, patients were selected exclusively with isolated valvular surgery, including valve replacement and/or repair. The overall long-term survival rates in patients with POAF were lower than those without POAF, which is consistent with previous report [7]. Furthermore, a propensity score model was performed to adjust the risk factors, which were potential contributors in increased mortality after cardiac surgery. The association of POAF persisted even after statistical adjustments of confounding variables. There was about $40 \%$ increase in patients with POAF after valve surgery, compared to patients without POAF. The result is consistent with the results conducted on patient with aortic valve replacement only, in which patient with POAF has about $40 \%$ increase in 10-year mortality than patients without POAF $[15,16]$.

\section{Limitation}

This study was limited as the general disadvantages of retrospective study. The most common bias in retrospective study is to control exposure of risk factors, especially formal exposure and condition. However, in this study, a matched patient group was used to make accurate comparisons between POAF and non-postoperative AF, which provided strange evidences.

\section{Conclusion}

Our present study supported that POAF is associated with an increased long-term mortality in patients who had isolated valve surgery. The contribution of POAF was independent of other variables which are related to the mortality in these patients.

\section{References}

1. Kern LS (2004) Postoperative atrial fibrillation: new directions in prevention and treatment. J Cardiovasc Nurs 19: 103-115; quiz 116-117.

2. Maisel WH, Rawn JD, Stevenson WG (2001) Atrial fibrillation after cardiac surgery. Ann Intern Med 135: 1061-1073.

3. Bramer S, van Straten AH, Soliman Hamad MA, van den Broek KC, Maessen JG, et al. (2011) New-onset postoperative atrial fibrillation predicts late mortality after mitral valve surgery. Ann Thorac Surg 92: 2091-2096.

4. Filardo G, Adams J (2010) Postoperative atrial fibrillation and late mortality after valvular surgery. Ann Thorac Surg 89: 2073; author reply 2073-2074.

5. Lotfi A, Wartak S, Sethi P, Garb J, Giugliano GR (2011) Postoperative atrial fibrillation is not associated with an increase risk of stroke or the type and number of grafts: a single-center retrospective analysis. Clin Cardiol 34: 787790.

6. Mariscalco G, Engstrom KG (2009) Postoperative atrial fibrillation is associated with late mortality after coronary surgery, but not after valvular surgery. Ann Thorac Surg 88: 1871-1876.

7. Silva RG, Lima GG, Laranjeira A, Costa AR, Pereira E, et al. (2004) Risk factors, morbidity, and mortality associated with atrial fibrillation in the postoperative period of cardiac surgery. Arq Bras Cardiol 83: 105-110; 99104.

8. Villareal RP, Hariharan R, Liu BC, Kar B, Lee VV, et al. (2004) Postoperative atrial fibrillation and mortality after coronary artery bypass surgery. J Am Coll Cardiol 43: 742-748.

9. Bramer S, van Straten AH, Soliman Hamad MA, Berreklouw E, Martens EJ, et al. (2010) The impact of new-onset postoperative atrial fibrillation on mortality after coronary artery bypass grafting. Ann Thorac Surg 90: 443-449

10. Benjamin EJ, Wolf PA, D'Agostino RB, Silbershatz H, Kannel WB, et al. (1998) Impact of atrial fibrillation on the risk of death: the Framingham Heart Study. Circulation 98: 946-952.

11. Wolf PA, Abbott RD, Kannel WB (1991) Atrial fibrillation as an independent risk factor for stroke: the Framingham Study. Stroke 22: 983-988.

12. Djaiani G, Phillips-Bute B, Podgoreanu M, Messier RH, Mathew JP, et al. (2004) The association of patent foramen ovale and atrial fibrillation after coronary artery bypass graft surgery. Anesth Analg 98: 585-589.

13. Asher CR, Miller DP, Grimm RA, Cosgrove DM 3rd, Chung MK (1998) Analysis of risk factors for development of atrial fibrillation early after cardiac valvular surgery. Am J Cardiol 82: 892-895.

14. Shinbane JS, Wood MA, Jensen DN, Ellenbogen KA, Fitzpatrick AP, et al. (1997) Tachycardia-induced cardiomyopathy: a review of animal models and clinical studies. J Am Coll Cardiol 29: 709-715.

15. Reber D, Birnbaum DE, Tollenaere P, Eschenbruch E (1996) Long-term results after aortic valve replacement with the mitroflow pericardial valve. $J$ Cardiovasc Surg (Torino) 37: 23-27.

16. Anderson ET, Hancock EW (1976) Long-term follow-up of aortic valve replacement with the fresh aortic homograft. J Thorac Cardiovasc Surg 72: 150-156. 